Acknowledgments: The author thanks all the investigators of the study: Costantino Cosimo, UO Medicina Riabilitativa, Azienda Ospedaliero-Universitaria di Parma, Italy; Fortina Mattia, Unità di Ortopedia Universitaria, AOU Senese Policlinico Santa Maria alle Scotte, Italy; Sadile Francesco, II Ortopedia - Ortopedia Infantile, Università degli studi di Napoli Federico II, Italy; Salini Vincenzo, Clinica Ortopedica e Traumatologica, Ospedale SS Annunziata di Chieti, Italy; Voglino Nicola, UO Ortopedia e Traumatologia, Ospedale Alto Tevere Città di Castello Azienda USL Umbria 1, Italy

Disclosure of Interests: Rocco Papalia Speakers bureau: Speaker for IBSA DOI: 10.1136/annrheumdis-2020-eular.4186

\section{AB0876 \\ THE BENEFIT AND SAFETY OF DIACEREIN IN AGED AND OBESE PATIENTS WITH SYMPTOMATIC KNEE OSTEOARTHRITIS: DATA FROM THE DISSCO CLINICAL STUDY}

J.P. Pelletier ${ }^{1}$, J. P. Raynauld ${ }^{2}$, M. Dorais ${ }^{3}$, P. Paiement ${ }^{4}$, J. Martel-Pelletier ${ }^{1}$. ${ }^{1}$ University of Montreal Hospital Research Centre (CRCHUM), Osteoarthritis Research Unit, Montreal, Canada; ${ }^{2}$ Institut de Rhumatologie de Montréal, Montreal, Canada; ${ }^{3}$ StatSciences Inc., Notre-Dame-de-l'Île-Perrot, Canada; ${ }^{4}$ ArthroLab Inc., Montreal, Canada

Background: The DISSCO trial (6-month international, multicentre, double-blind, randomised study on the effect of diacerein vs celecoxib in symptomatic knee osteoarthritis [OA] patients) showed that diacerein had comparable efficacy to celecoxib at reducing the level of pain (WOMAC pain).

Objectives: To assess the effect of age, body mass index (BMI), and gender on the efficacy/safety profile of diacerein following 6 months of treatment.

Methods: Of the patients $(n=380)$ that were randomised, 186 received treatment with $50 \mathrm{mg}$ diacerein once daily for the first month and twice daily thereafter. This study was done on the intent-to-treat population $(n=183)$. Efficacy outcome assessments which included absolute change in WOMAC pain (score 0-50) and function (score 0-170), and VAS (score 0-10) were analysed following stratification based on age ( $<65$ vs $\geq 65$ years old) and BMI $\left(<30 \mathrm{vs} \geq 30 \mathrm{~kg} / \mathrm{m}^{2}\right)$ at time of randomisation. Treatment effects on continuous efficacy outcomes were performed using covariance analysis (ANCOVA). For gastrointestinal (GI) safety outcomes, the adverse events (AEs), including diarrhoea, soft faeces, abdominal pain and dyspepsia, and the time-to-onset from baseline were stratified according to age of patients at randomisation. Treatment-related GI AEs were also assessed according to the gender. The independent variables were treatment, stratification variable, interaction between both, and the outcome measure at baseline. Comparisons between groups were carried out using Chi-square.

Results: No significant differences were found between the two age groups ( $<65$ years old [ $n=105], \geq 65$ years old $[n=78]$ ) in the level of reduction in WOMAC pain $(-10.3 \pm 1.1,-8.6 \pm 1.3$, respectively; $p=0.30)$, VAS $(-2.3 \pm 0.2,-2.2 \pm 0.3$ $p=0.73)$ or improved physical function $(-29.7 \pm 3.7,-22.1 \pm 4.2, p=0.18)$. The reported incidences of treatment-related GI AEs were also similar between the two age groups; more specifically for diarrhoea, incidence for patients $<65$ years old [ $n=12] 11.3 \%$ and for those $\geq 65$ years old $[n=7] 8.8 \%(p=0.63)$ with a mean time-to-onset (day $43 \pm 49,61 \pm 51$, respectively; $p=0.11$ ). Moreover, gender had no influence on treatment-related GI AEs $(p=0.42)$

In regard to treatment response of obese $(n=101)$ vs. non-obese $(n=82)$ patients in terms of pain reduction (WOMAC: $-10.1 \pm 1.2,-9.1 \pm 1.1$, respectively; $p=0.58$; VAS: $-2.6 \pm 0.3,-2.0 \pm 0.3 ; p=0.15)$, or improved WOMAC physical function $(-29.8$ $\pm 4.2,-23.5 \pm 3.8 ; p=0.26$ ), there were also no significant differences.

Conclusion: In symptomatic knee OA patients, the level of effectiveness and safety profile of treatment with diacerein were found not to be influenced by age, BMl or gender.

Disclosure of Interests: Jean-Pierre Pelletier Shareholder of: ArthroLab Inc. Grant/research support from: TRB Chemedica, Speakers bureau: TRB Chemedica and Mylan, Jean-Pierre Raynauld Consultant of: ArthroLab Inc., Marc Dorais Consultant of: ArthroLab Inc., Patrice Paiement Employee of: ArthroLab Inc. Johanne Martel-Pelletier Shareholder of: ArthroLab Inc., Grant/research support from: TRB Chemedica

DOI: 10.1136/annrheumdis-2020-eular.1862

\section{AB0877 1 CLINICAL EFFICACY AND SAFETY PROFILE OF TOPICAL ETOFENAMATE IN THE TREATMENT OF PATIENTS WITH MUSCULOSKELETAL DISORDERS: RESULTS OF A SYSTEMATIC REVIEW}

A. Pereira ${ }^{1,2,3,4}$, D. Marinho ${ }^{5} .{ }^{1}$ CINTESIS - Health Technology and Services Research Center (Ageing-C), Porto, Portugal; ${ }^{2}$ University of Aveiro, Department of Education and Psychology, Aveiro, Portugal; ${ }^{3}$ Institute of Biomedical Sciences Abel Salazar, University of Porto, Porto, Portugal; ${ }^{4} \mathrm{CMV}$-Viseu
Medical Center - Coimbra Rehabilitation Institute, Coimbra, Portugal; ${ }^{5} B I A L$, Medical Affairs Department, Trofa, Portugal

Background: Musculoskeletal disorders affect millions of people of all ages around the world [1]. Nonsteroidal anti-inflammatory drugs (NSAIDs) are, in general, the cornerstone of musculoskeletal pain management; however, systemic adverse events with oral formulations of NSAIDs are common. To address this, topical formulations of some NSAIDs have been developed. [2] Although there are many nonsteroidal anti-inflammatories, only a few are used as local therapeutics. This is because the physicochemical properties of these substances, which were originally developed for oral administration, frequently do not guarantee a satisfactory pharmaceutical formulation with satisfactory topical absorption. [3]

Objectives: The aim of this systematic review was to assess the available evidence on the efficacy and safety of the topical formulations of the NSAID etofenamate in patients with musculoskeletal disorders.

Methods: A systematic search of PubMed and Web of Science was conducted, using the key words (topical etofenamate efficacy) OR (topical etofenamate safety) OR (topical etofenamate effectiveness) to identify studies of etofenamate published from inception to November 2018. Some published manuscripts of interest known by the authors but not identified in the PubMed search were also added to ensure the review article was as comprehensive as possible.

Results: Overall, 12 studies were identified. [3-14] These studies demonstrated the ability of topical etofenamate (administered either in gel [ $5 \%$ or $10 \%]$, cream [ $10 \%]$ or lotion [10\%] formulations]) to improve pain and reduce inflammation in patients with musculoskeletal disorders, including blunt injuries and rheumatic diseases Etofenamate was shown to have an overall efficacy that was superior to other topical NSAIDs, such as $1 \%$ indomethacin and $1 \%$ diclofenac, and to be as effective as topical formulations of $2.5 \%$ ketoprofen gel and $2 \%$ ketorolac gel (although ketorolac suggested a better elimination of pain at some time points). Overall, when compared to placebo, etofenamate gel $5 \%$ demonstrated significant better results in the reduction of pain symptoms (with or without combination with ultraphonophoresis) Furthermore, clinical evidence indicates that etofenamate is generally well tolerated in these indications.

Conclusion: The available clinical evidence suggests that etofenamate could be an effective therapeutic option for the management of musculoskeletal disorders, such as blunt traumas, lumbago or osteoarthritis. However, larger and well-controlled clinical trials comparing the efficacy and safety of etofenamate with other newer topical NSAIDs are warranted.

References:

[1] Atchison JW, et al. J Manag Care Pharm. 2013; 19: S3-19.

[2] Haroutiunian S, et al. Pain Med. 2010; 11: 535-49.

[3] Pelster B, et al. ZFA. 1992; 68: 364-7.

[4] Schneider H. Therapiewoche. 1983;33:5809-18.

[5] Miehlke RK, et al. Med Welt. 1985;36:103-6.

[6] Rechziegler H, et al. Therapiewoche. 1986;36:5347-51.

[7] Hallmeier B. Rheuma. 1988;8:183-6.

[8] Rechziegler H. Therapiewoche. 1983;33:703-7.

[9] Matsuno S, et al. J Med Pharm Sci. 1983;9:349-67.

[10] Nagaya I, et al. Med Pharmacy. 1982;8:1549-82.

[11] Ascher R, et al. Fortschr Med. 1982;37:1729-34.

[12] Billigmann P, et al. Praktische Traumatologie Sportmedizin. 1992;2:72-7.

[13] Diebschlag W, et al. J Clin Pharmacol. 1990;30:82-9.

[14] Matucci-Cerinic M, et al. Int J Clin Pharmacol Res. 1988;8:157-60

Disclosure of Interests: Anabela Pereira Consultant of: Recently, I was a paid consultant of Bial., Speakers bureau: I have been a paid speaker for Bial., Daniela Marinho Employee of: I'm currently an employee of BIAL pharmaceutical company. I belong to the medical affairs department of Bial.

DOI: 10.1136/annrheumdis-2020-eular.382

\section{\begin{tabular}{|l|l}
\hline AB0878 THE COMPARISON EFFECTS OF INTRA-ARTICULAR \\
\hline
\end{tabular} INJECTION OF PLATELET RICH PLASMA (PRP), PLASMA RICH IN GROWTH FACTOR (PRGF), HYALURONIC ACID (HA), AND OZONE IN KNEE OSTEOARTHRITIS; A ONE YEAR RANDOMIZED CLINICAL TRIAL}

S. A. Raeissadat ${ }^{1}$, P. Ghazi Hosseini ${ }^{1}$, M. H. Bahrami ${ }^{1}$, R. Salman Roghani ${ }^{1}$, M. Fathi ${ }^{1}$, A. Gharooee Ahangar ${ }^{1}$, M. Darvish ${ }^{1} .{ }^{1}$ Shahid Beheshti University of Medical Sciences, Tehran, Iran (Islamic Republic of)

Background: Knee osteoarthritis (OA) as a common progressive degenerative condition is one of the most important leading causes of disability and relative dependence. Worldwide prevalence of symptomatic knee OA has estimated $3.8 \%$. It affects more than $20 \%$ of over 45 -year-old population. Among the minimally invasive methods recommended for knee OA management is intra-articular injections for which a large array of products have been used. Despite all the 
existing options, there is still no general consensus on the choice and priority of the best intra-articular injection in knee osteoarthritis.

Objectives: Our study compare the short and long-term efficacy of the intra articular injections (IAIs) of hyaluronic acid (HA), platelet-rich plasma (PRP), plasma rich in growth factors (PRGF), and ozone in patients with knee osteoarthritis (OA). Methods: In this single-blinded randomized clinical trial, 238 patients with mild to moderate knee OA were randomized into4 groups of IAls: HA (3 doses weekly), PRP (2 doses with 3 weeks interval), PRGF ( 2 doses with 3 weeks interval), and Ozone (3 doses weekly). Our outcome measures were the mean changes from baseline until 2,6, and 12 months post intervention in scores of visual analog scale, Western Ontario and McMaster Universities Osteoarthritis Index (WOMAC), and Lequesne index. Results: A total of 200 patients enrolled final analysis. The mean age of patients was $56.9 \pm 6.3$ years, and69.5\% were women. In 2 months follow up, significant improvement of pain, stiffness, and function were seen in all groups compared to the baseline, but the ozone group had the best results $(P<0.05)$. In 6 month follow up HA, PRP, and PRGF groups demonstrated better therapeutic effects in all scores in comparison with ozone $(P<0.05)$. At the end of the 12th month, only PRGF and PRP groups had better results versus $\mathrm{HA}$ and ozone groups in all scores $(P<0.05)$. Despite the fact that ozone showed better early results, its effects begin to wear off earlier than other products and ultimately disappear in 12 months. Conclusion: Ozone injection had rapid effects and better short-term results after 2 months, but its therapeutic effects did not persist after 6 months and at the 6-month follow up, PRP,PRGF and HA were superior to ozone. Only patients in PRP and PRGF groups improved symptoms persisted for 12 months. Therefore, these products could be the preferable choices for long-term management.

References:

[1] Wang-Saegusa A, Cugat R, Ares O, Seijas R, Cuscó X, Garcia-Balletbó $M$. Infiltration of plasma rich in growth factors for osteoarthritis of the knee short-term effects on function and quality of life. Archives of orthopaedic and trauma surgery. 2011;131(3):311-7.

[2] De La Mata J. Platelet rich plasma.A new treatment tool for the rheumatologist?ReumatologíaClínica (English Edition). 2013;9(3):166-71.

[3] Raeissadat SA, Rayegani SM, Sedighipour L, Bossaghzade Z, Abdollahzadeh $\mathrm{MH}$, Nikray R, et al. The efficacy of electromyographic biofeedback on pain, function, and maximal thickness of vastus medialis oblique muscle in patients with knee osteoarthritis: a randomized clinical trial. Journal of pain research. 2018;11:2781.

[4] Lawrence RC, Felson DT, Helmick CG, Arnold LM, Choi H, Deyo RA, et al. Estimates of the prevalence of arthritis and other rheumatic conditions in the United States: Part II. Arthritis \& Rheumatism. 2008;58(1):26-35.

[5] Tehrani-Banihashemi A, Davatchi F, Jamshidi AR, Faezi T, Paragomi P, Barghamdi M. Prevalence of osteoarthritis in rural areas of I ran: a WHO-ILAR COPCORD study. International journal of rheumatic diseases. 2014;17(4):384-8.

[6] Rayegani SM, Raeissadat SA, Heidari S, Moradi-Joo M. Safety and effectiveness of low-level laser therapy in patients with knee osteoarthritis: a systematic review and meta-analysis. Journal of lasers in medical sciences. 2017;8(Suppl 1):S12.

Disclosure of Interests: None declared

DOI: 10.1136/annrheumdis-2020-eular.513

\section{AB0879 DOES BODY WEIGHT INFLUENCE THE KNEE INJURY AND OSTEOARTHRITIS OUTCOME SCORE IN PERSONS WITH SYMPTOMATIC KNEE OSTEOARTHRITIS?}

A. Ben Tekaya ${ }^{1}$, L. Rouached ${ }^{1}$, A. Slimi ${ }^{2}$, J. Galalou ${ }^{3}$, E. Bahlouli ${ }^{3}$ O. Saidane ${ }^{1}$, S. Bouden ${ }^{1}$, R. Tekaya ${ }^{1}$, I. Mahmoud ${ }^{1}$, L. Abdelmoula ${ }^{1} .{ }^{1}$ Charles Nicolle Hospital, Rheumatology, Tunis, Tunisia; ${ }^{2}$ Community Health Center, Kef, Tunisia; ${ }^{3}$ Physical and Rehabilitation Medicine Department, Djebel Oust, Tunisia

Background: Overweight is a major risk factor for the development and progression of knee osteoarthritis (OA). Weight loss for patients with knee OA has been associated with improvement in self-reported pain and function and is recommended by EULAR as part of the therapeutic management.

Objectives: The aim of the study was to evaluate the relation between overweight and functional impairment in adults with knee OA.

Methods: It was a prospective study conducted in a rheumatologic department over a 4 months period. Patients with symptomatic knee OA based on the ACR criteria, were included. A screening of body mass index (BMI) was carried out for all patients. It was categorized following the WHO classification into: normal $(<25 \mathrm{~kg} / \mathrm{m} 2$ ), overweight $(25$ to $<30$ ), obese (up to 30 ).

Pain level was evaluated using the Visual Analogue Scale (VAS). Function was assessed by the short form of the Knee injury and Osteoarthritis Outcome Score (KOOS-PS) (KOOS-PS scores to 0 representing no difficulty and 100 representing extreme difficulty). The patients' knee radiographies were graded according to Kellgren Lawrence criteria $(\mathrm{KL})$. The patients were allocated in two groups; as grade I-II KL (Group 1) and grade III-IV KL (Group 2).

Results: We included 143 patients with a mean age of $65.17 \pm 10.7$ years and $88.1 \%$ of women. Patients were from low socio-economic class in $30.8 \%$ of cases. Mean disease duration of the KOA was 5.4 years [3months-20 years] and mean BMI was $31.8 \pm 5.6 \mathrm{~kg} / \mathrm{m}^{2}$. Patients were with normal weight in $16.1 \%$, overweight in $19.6 \%$ and obese in $64.3 \%$

Knee OA was bilateral in $85.3 \%$ and other OA sites were associated in $37.8 \%$ of patients. Mean VAS pain of knee OA was $6.6 \pm 1.5$ and KOOS-PS was $48.8 \pm 16.5 / 100$. Concerning the radiographic damage; we found grade I-II (KL) in $22.6 \%$ and grade III-IV (KL) in $77.4 \%$.

High $\mathrm{BMI}$ (BMl $\geq 25 \mathrm{~kg} / \mathrm{m}^{2}$ was not significantly associated with worse KOOS score $(p=0.9)$, more pain $(p=0.5)$ or an increasing severity of radiological knee osteoarthritis $(p=0.14)$. Moreover, the level BMI was not associated with the presence of other OA sites $(p=0.9)$ or a bilateral KOA $(p=0.07)$.

Conclusion: These data, from a subset of participants with symptomatic radiographic knee OA, demonstrate no correlation between obesity and pain, functional impairment and radiographic severity.

Acknowledgments: none

Disclosure of Interests: None declared

DOI: 10.1136/annrheumdis-2020-eular.5643

\section{AB0880 NEUROPATHIC PAIN IN PATIENTS WITH KNEE OSTEOARTHRITIS: PREVALENCE AND RELATED FACTORS}

A. Ben Tekaya ${ }^{1}$, L. Rouached ${ }^{1}$, A. Slimi ${ }^{2}$, O. Saidane ${ }^{1}$, S. Bouden ${ }^{1}$, R. Tekaya ${ }^{1}$, I. Mahmoud ${ }^{1}$, L. Abdelmoula ${ }^{1} .{ }^{1}$ Hospital Charles Nicolle, Rheumatology, Tunis, Tunisia; ${ }^{2}$ Community Health Center, Kef, Tunisia, Kef, Tunisia

Background: Discordance between radiographic and pain severity in osteoarthritis (OA) has led researchers to investigate other pain mechanisms, including neuropathic pain (NP). Recent meta-analysis concluded that NP prevalence in people with knee or hip OA was $23 \%$ [1].

Objectives: The primary objective of this study was to determine the prevalence of NP in patients with painful knee OA. Secondarily, we evaluated the relationship between NP and pain intensity, function and radiographic severity of knee OA. Methods: This cross-sectional study enrolled patients with knee OA (ACR criteria) from a rheumatology outpatient Hospital over a four-month period. Exclusion criteria were: knee surgery, chronic conditions of the nervous system, cognitive or psychiatric disorders. The patient's characteristics and pain severity using the Visual Analogue Scale (VAS) were evaluated. The NP was assessed according to the Douleur Neuropathique 4 questionnaire (DN4) (arabic valid version). Functional impairment was estimated using the short form of the Knee injury and Osteoarthritis Outcome Score (KOOS-PS) (KOOS-PS scores to 0 representing no difficulty and 100 representing extreme difficulty). Radiographs were rated using the Kellgren Lawrence (KL) grade classification (I-IV). Statistical analysis was performed to find the factors closely related with NP.

Results: Ninety three patients with knee OA were included in the study. The mean age was $65.03 \pm 18.5$ years with a sex ratio of 0.08 . Mean duration of symptoms was 3.5 years [3months-20 years]. Concerning the marital status: $53.8 \%$ were married, $34.4 \%$ were widow and $10.8 \%$ were divorced. The majority of patients were illiterate $(65.6 \%)$ and only $2.2 \%$ went to university. Patients were from low socio-economic class in $37.6 \%$ of cases. At least one comorbidity was revealed for $90.3 \%$ of patients and their mean BMI was $31.6 \pm 6.3$ [19.9-52.3] Concerning the clinical features of the KOA, mean VAS pain was $6.6 \pm 1.6$ and KOOS-PS was $45.6 \pm 18.5$. Of the subjects, $22.6 \%$ have radiographic at grade II, $57 \%$ at grade III and $20.4 \%$ at grade IV based on $\mathrm{KL}$ grading.

The mean (SD) score by the study participants on the DN4 was $4.9 \pm 2.4$. The prevalence of NP (DN4 $\geq 4)$ was $71 \%$.

A DN4 score $\geq 4$ was significantly associated with the VAS pain $(p=0.00)$ and the KOOS-PS $(p=0.00)$ and the presence of comorbidity $(p=0.04)$. However, there was no significant relation between DN4 score and, age, sex, marital status socio economic class, level of education, $B M I$ and $K L$ grade $(p=0.7, p=0.08$, $p=0.7, p=0.3, p=0.7, p=0.7, p=0.6$ )

Conclusion: Our results highlight the high frequency of NP in patients with knee OA according to the DN4. Knee OA patients with NP encounter clinically relevant functional limitation. Thus, it is important to be aware of this neuropathic component to ensure appropriate management in the treatment of knee OA pain.

[1] French HP, Smart KM, Doyle F. Prevalence of neuropathic pain in knee or hip osteoarthritis: A systematic review and meta-analysis. Semin Arthritis Rheum. 2017;47(1):1-8.

Acknowledgments: none

Disclosure of Interests: None declared

DOI: 10.1136/annrheumdis-2020-eular.3740 